\title{
Exploring Grey Systems Theory-Based Methods and Applications in Analyzing Socio-Economic Systems
}

\author{
Ehsan Javanmardi *(1) and Sifeng Liu \\ Institute for Grey Systems Studies, Nanjing University of Aeronautics and Astronautics, Nanjing 211106, China \\ * Correspondence: ejavanmardi@nuaa.edu.cn
}

Received: 7 July 2019; Accepted: 1 August 2019; Published: 2 August 2019

check for

updates

\begin{abstract}
The present study seeks to provide an overview of studies dealing with the grey systems theory from the perspective of socio-economic systems. A scoping review is conducted to explore the studies focusing grey systems theory and its applications in socio-economic systems. The publications selected for analysis were collected through searching the databases of the Web of Science, Scopus, and Science Direct. The publications were selected from 2010 to 2019, and the following keywords were used to detect them: grey systems, grey relational, grey model, grey prediction, grey control, grey incidence, grey cluster, grey decision, and grey input-output plus social, economic, and socioeconomic. Out of the 2375 records found, 147 full papers were screened. Results obtained from the studies were separated into the following categories: social network, healthcare, financial issues, sustainability, tourism, social and cultural, public sectors, urbanization, development, business, economics, demographics, innovation, and entrepreneurship. Findings showed that complexity, uncertainty, and a lack of access to a large collection of data directed researchers to rely on grey systems theory-based socio-economic systems. Furthermore, theory-based grey systems were more effective than other approaches of decision-making and analysis. Drawing on the grey systems theory-based holistic approaches and systems thinking methods helped to obtain better results in analyzing socio-economic systems.
\end{abstract}

Keywords: grey systems theory; social and economic systems; grey model; uncertain systems; grey relational analysis; grey prediction; grey model

\section{Introduction}

Aristotle's conviction that knowledge is not obtained through the examination of separate components but rather arises from an understanding of the whole (Aristotle's holism) inspired some scholars to present the systems theory and its derivatives [1]. It became abundantly clear that entities in the real world could not be sufficiently understood with an only reference to the nature of their components, but the organization of the components was remarkable as well. Thus, it was acknowledged that complex things are in fact "systems" in themselves, structures that function as wholes because of the relationships between their parts [2].

The system theory perceives the world as a system of interacting segments that can be determined by a network of relationships. This viewpoint is more flexible than the models that regard the world as a device, a mechanism, or even an organism [3]. There are innumerable systems exhibiting such characteristics, including natural systems such as the human body, the earth, and space, and even human-made systems [4]. A central hypothesis of the systems viewpoint suggests that everything we encounter is a system or part of one [5].

Systems science reveals the deeper and more intrinsic interconnections of objects/events and has significantly contributed to the overall progress of science and technology. At the end of the first half of the twentieth century, systems theory, information theory, and cybernetics emerged. Toward the 
beginning of the 1970s, a collection of theories was proposed, including dissipative structures, synergics, catastrophe, and bifurcations. In late 1970s, new transfield and interfield systems theories came to the fore one after another, such as the ultracircular theory, dynamic systems, and pansystems [6].

One of the most momentous and possibly the most complex types of systems are social and economic (socio-economic) systems [7]. Systems of this sort represent complex structures consisting of social and economic elements. Such systems subsume a complex mix of individuals, groups, institutions, and organizations that are interlinked on different levels in terms of economy and society. The systems are made up of humans, and especially the relationships between them and their role. Socio-economic systems do not exclusively focus on humans, but they also consider the role of humans in systems surrounding them. The experiential world in such systems is associated with human life and society in all their complexity and enrichment [8]. The phrase "Socioeconomics" can point generally to the application of economics in the scrutiny of society [9]. A common belief among many scholars is that the world which we live in is a world of socio-economic systems [10].

During the second half of the twentieth century, the seemingly incessant emergence of various theories and methodologies concerned with uncertain systems was remarkable in the areas of systems science and systems engineering. For example, Zadeh initiated fuzzy set theory in 1965, and the rough set theory was presented by Pawlak in the 1980s [11]. Grey system theory (GST) is a sub-type of systems theory, which emerged in the 1980s. The idea of grey system was first suggested by Chinese scientist Julong Deng in a paper entitled The Control Problems of Grey Systems [12]. Soon after its introduction, the theory was regarded as an interesting way of understanding, modelling and incorporating uncertainty in systems analysis, especially when the recorded data were meager [13]. Over thirty-five years have passed by since the first grey system proposed proved to be successful. Over this time, numerous ideas and models have addressed GST, while many successful practical solutions to various problems have been published in many different fields [14]. These practical applications have brought about definite and noticeable social and economic benefits [15].

GST seeks to construct theories, techniques, notions, and ideas for resolving/analyzing latent and intricate systems [16]. A typical GST can be effectively used for problems with limited sample size and insufficient information. GST makes it possible to produce meaningful and useful information as soon as possible in systems under uncertainty and with partial information. As such, the functional behavior of the system can be properly defined and effectively monitored [17].

Without a doubt, human perception of the real world is gained through filters. Our evaluations and measurements is accompanied by distortions, delays, aberration, biases, errors, and other defects, some of which are known but others are unknown (or even unknowable) [18]. Therefore, in the natural and physical world, most systems in ecological environments, societies, economies, scientific research, and the like remain complicated and uncertain systems that are recognized by insufficient samples and poor information [11]. The complexity of systems suggests that human understanding of the implications of objective systems may be based on poor information. That is why these systems should be seen as grey [19], and for the same reason GST can prove to have wide-ranging applications [15]. Due to the inherent human incapability of fully understanding and having access to all pieces of information about a phenomenon/system, knowledge produced remains incomplete, because uncertainty can occur from deficient methods of data storage, as well as defective means of data collection/transition. Uncertainty is a common phenomenon specially in socio-economic systems as they are mainly arranged by people and have more complexity [20]. Uncertainty in this area results from a whole array of factors such as ability for innovation, random behavior, personal subjective patterns, indeterminate response to external stimuli, and idiosyncratic individuals or systems [21].

In daily social economic and scientific research activities, there are many situations relying on imperfect information. In a general socio-economic system, it is difficult to analyze the effect of the input on the output because there are no ideally defined borders between the "interior" (the system) and the "exterior" (the environment); in fact, it would be difficult to determine the boundary of a system [22]. Therefore, research regulated by grey systems postulates and models can effectively help 
control and govern important social and economic parameters [15]. Given the increasing development of GST and the numerous areas in which it has been used, it would be necessary to review the consequences of GST in the analysis of socio-economic systems.

This study seeks to provide an up-to-date overview of studies dealing with GST, from the perspective of socio-economic systems, with the purpose of tracing the diversity of topics in this field and clarifying the topics that could inspire future research directions. The paper underlines the main research areas within GST in relation to socio-economic systems and their related issues, as an informative summary for further research. For this purpose, all the papers published in this field are considered and extracted from the Web of Science (WoS), Science Direct (SD), and Scopus. To highlight the scientific progress of the field, a scoping review is conducted through the use of keywords such as grey systems, grey relational, grey model, grey prediction, grey control, grey incidence, grey cluster, grey decision, grey input-output, in addition to social, economic, and socio-economic. Primarily, the different domains are specified in which socio-economic systems have been approached with reference to GST. Then, a review of GST methods in social and economic areas is presented. Finally, both the benefits and effects of GST-based methods and their applications in socio-economic systems are discussed.

\section{Theoretical Background}

The intersections of economic and social environments give rise to many modern complex scientific problems which need to be addressed through different fields of systems theory. These new theories have helped deepen our understanding of the evolution of physical nature and subjective issues [19]. GST is a comparatively new approach that concentrates on the study of systems involving small samples and poor information [11]. GST emerged from the system theory [23]. GST is a complicated theory that rests on knowledge systems, conceptions, and methods, while addressing determinism, randomization, and chaos theory in practice [24].

The main characteristic of uncertain systems is the incompleteness and inadequacy of their data. Incomplete information is a common phenomenon in our social, economic, and scientific research activities. Incompleteness in available information is absolute, while completeness in information is relative [15]. There are four common cases regarding incomplete system information: incomplete element (parameter) information; incomplete structure information; incomplete boundary information; and incomplete operation behavior information [25]. Furthermore, the origins of imprecision are unquantifiable information, non-obtainable information, incomplete information, and partial ignorance [26].

Another fundamental characteristic of uncertain systems is naturally occurring inaccuracy (uncertainty) in available data. Given the causes of uncertainties, inaccuracies can be categorized into three types: the conceptual, level, and prediction type inaccuracies [11]. Normally, social, economic, agricultural, industrial, ecological, biological, and other systems are defined by the features of classes of objects identified in them, while grey systems are specified using the color of the systems in question [27].

If all the information is known in a system, it is defined as a "white system". If we do not have any information about the system, it is defined as a "black system", and if we have partial information about a system, it is called a "grey system" [28]. The concept of grey numbers emerged from GST, and it deals with the decisions in uncertain real-world environments (characterized by incomplete information). In GST, information can be classified into three levels: white numbers, grey numbers, and black numbers. A black number, usually there when your information is too vague about an indicator, has neither upper nor lower values of limits, whereas the upper and the lower limits are all grey numbers. Therefore, it is believed to contain no meaningful information. In contrast, the white number is an exact number; the lower limit is equal to the upper limit, which provides complete information. A grey number has upper and lower limits with limited information, the exact value of which is unknown, but the interval within which the value lies is known [29]. 
The six basic axioms of GST, containing intrinsic philosophical postulates, are as follows [30]:

- Axiom 1: "Difference" connotes the existence of information. Each piece of information must carry some kind of "difference" which is known as principle of informational differences;

- Axiom 2: The solution to any problem with imperfect and indefinite information is not unique which is known as principle of non-uniqueness;

- Axiom 3: Making the most and best use of the available "minimal amount of information" which is known as principle of minimal information;

- Axiom 4: Information is the base on which people recognize and understand things (e.g., nature) which is known as principle of recognition base;

- Axiom 5: The function of new pieces of information is greater than that of old pieces of information which is known as principle of new information priority;

- Axiom 6: "Incompleteness" of information is absolute which is known as principle of absolute greyness.

In addition, GST rests on some major presuppositions: (a) the theoretical system is developed based on the grey algebraic system, grey equations, grey matrices, etc.; (b) the methodological system is established according to sequence operators and generations of grey sequences; (c) the analysis and evaluation system is constructed on the basis of grey incidence spaces and grey cluster evaluations; (d) the prediction model system is centered around GM(1.1); (e) the decision-making model system is illustrated by multi-attribute intelligent grey target decision models; (f) the system of combined grey models is innovatively developed for generating new and practically efficient results; and $(\mathrm{g})$ the optimization model generally contain of grey programming, grey input-output analysis, grey game theory, and grey control [6]. The superlative characteristic of GST is that it converts data series linearly through grey generation methods to reduce the variation of the original data series [23].

Over 35 years, GST has guided winsome usages in many countries of the world, bringing about a large number of achievements [15]. Some subsidiary disciplines, such as grey geology, grey hydrology, grey breeding, and grey medical science, have emerged based on GST postulates [28]. However, the theory still needs to be further developed and improved to provide more contributions. Yet, given the complex and dynamic nature of socio-economic systems, GST can significantly help analyze these systems. Certainly, social-economic systems involve dynamic complexity, which arises because such systems are dynamic, tightly coupled, nonlinear, governed by feedback, self-organizing, adaptive, history-dependent, policy resistant, counterintuitive, and characterized by trade-offs (Sterman, 2009).

\section{Methods}

This scoping review sought to provide an overview and summary of up-to-date studies focusing on GST and its applications in socio-economic systems. A four-step scoping review was directed: (a) locating and recognizing related publications; (b) screening the located publications; (c) evaluating full-text publications for inclusion or exclusion; and (d) a detailed inspection of the 28 articles included.

\subsection{Search Strategy and Eligibility Criteria}

Literature searches were conducted on WoS, Scopus, and Science Direct (SD), between September 2018 and March 2019. The period under study spanned from 2010 to the first quarter (Q1) of 2019, and the following keywords were used for the electronic search: grey systems, grey relational, grey model, grey prediction, grey control, grey incidence, grey cluster, grey decision, grey input-output, in addition to social, economic, and socioeconomic. The range of the keywords selected made it possible to include all possible articles in the search procedures. The keywords were searched with quotation marks to find publications with exact keywords.

Furthermore, all documents were selected for the initial search, but for the final screening only two types of publications were considered eligible for the purpose of this research: articles and reviews. These two types included the following publications: review articles, research articles, data articles, 
book reviews, mini-reviews, product reviews, and video articles. To better understand the growth process of GST, the initial searches were conducted in three periods: 1999 and earlier, from 2000 to 2009, and between 2010 and Q1-2019. The search results are shown in Table 1. Obviously, the number of publications concerned with GST has grown continuously and dramatically since 2000.

Table 1. Numbers of papers in each database as a result of the query grey systems theory (GST) plus the keywords.

\begin{tabular}{|c|c|c|c|c|c|c|c|c|c|}
\hline \multirow{2}{*}{ Keywords } & \multicolumn{3}{|c|}{1999 \& Earlier } & \multicolumn{3}{|c|}{$2000-2009$} & \multicolumn{3}{|c|}{ 2010-2019 } \\
\hline & SD & WOS & Scopus & SD & wos & Scopus & SD & WoS & Scopus \\
\hline Grey Relation (GR) & 7 & 128 & 42 & 105 & 1209 & 1128 & 656 & 3709 & 4724 \\
\hline GR \& Social Economic & 4 & 8 & 5 & 29 & 97 & 197 & 139 & 352 & 1070 \\
\hline Grey Model (GM) & 24 & 104 & 109 & 67 & 749 & 837 & 301 & 1400 & 2136 \\
\hline GM \& Social Economic & 0 & 6 & 15 & 3 & 65 & 150 & 40 & 157 & 636 \\
\hline Grey System (GS) & 20 & 290 & 145 & 63 & 3,496 & 1475 & 158 & 7180 & 2107 \\
\hline GS \& Social Economic & 2 & 18 & 20 & 8 & 333 & 291 & 16 & 861 & 606 \\
\hline Grey Prediction (GP) & 4 & 70 & 36 & 40 & 486 & 439 & 101 & 923 & 1152 \\
\hline GP \& Social Economic & 0 & 3 & 2 & 2 & 19 & 54 & 14 & 111 & 331 \\
\hline Grey Control (GC) & 2 & 7 & 9 & 2 & 30 & 35 & 2 & 20 & 42 \\
\hline GC \& Social Economic & 0 & 0 & 0 & 0 & 6 & 6 & 0 & 3 & 10 \\
\hline Grey incidence (GI) & 0 & 1 & 1 & 7 & 198 & 182 & 29 & 381 & 390 \\
\hline GI \& Social Economic & 0 & 0 & 1 & 1 & 32 & 49 & 8 & 57 & 135 \\
\hline Grey Cluster (GCL) & 1 & 9 & 9 & 10 & 60 & 59 & 30 & 91 & 119 \\
\hline GCL \& Social Economic & 0 & 1 & 1 & 0 & 8 & 13 & 3 & 13 & 32 \\
\hline Grey Decision (GD) & 2 & 11 & 4 & 5 & 72 & 54 & 20 & 91 & 107 \\
\hline GD \& Social Economic & 0 & 1 & 1 & 0 & 4 & 9 & 7 & 18 & 43 \\
\hline Grey Input-Output (GIO) & 0 & 1 & 0 & 2 & 4 & 5 & 0 & 8 & 6 \\
\hline GIO \& Social Economic & 0 & 1 & 0 & 2 & 3 & 4 & 0 & 2 & 4 \\
\hline \multicolumn{7}{|c|}{ Total Grey Publications (2010-2019) } & 1297 & 13,803 & 10,783 \\
\hline \multicolumn{7}{|c|}{ Total Grey publications after removing duplicates (2010-2019) } & 1083 & 10,014 & 9476 \\
\hline \multicolumn{7}{|c|}{ Total Grey and “Social Economic" Publications (2010-2019) } & 227 & 1574 & 2867 \\
\hline \multicolumn{7}{|c|}{ Total Grey and "Social Economic" publications after removing duplicates (2010-2019) } & 103 & 1148 & 2450 \\
\hline \multicolumn{7}{|c|}{ Total Grey and "Social Economic" publications limited to article and review (2010-2019) } & 100 & 685 & 1590 \\
\hline
\end{tabular}

The total number of publications in all databases (including social and economic), in terms of various grey-related keywords, was 20573 studies from 2010 to Q1-2019. Out of this number, 1083 studies were indexed in Science Direct, 10014 ones in the WoS databases, and 9476 ones in Scopus. A group of studies was selected for further investigation; these studies displayed the following conditions simultaneously to be included: (a) they contained at least one of the keywords associated with GST; (b) they included one of the keywords, social, economic or socio-economic; and (c) they were published after 2010. The search in the WoS database focused on keywords in the "topic" and "all databases". In the WoS databases, 1148 publications were identified with these properties. Then the search was limited to "article" and "review" publications. This criterion reduced the initial set of papers to a total of 685 research articles, which were selected for further processing.

The search on the Science Direct and the Scopus databases focused on the presence of keywords in the "title, abstract, or keywords" sections. The Scopus database yielded 2450 results for all publications. After the findings were filtered through "Article or Review", the number was cut down to 1590. A total of 103 results were found in the Science Direct search, and after they were filtered through "Review" and "Article", the figure was reduced to 100. The distribution of publications by keywords is shown in Table 1. Furthermore, in Figure 1, the trend of the total number of publications between 2010 and Q1-2019 in the field of GST-based socio-economic studies indexed in the databases is illustrated according to years of publication. Clearly the number of the articles in this area has grown steadily, which demonstrates that more researchers have worked on GST and its application in analyzing socioeconomic issues. The framework primarily used the search tools of the libraries with the aforementioned keywords; next, after eliminating duplicate records from the retrieved papers, it analyzed the title, abstract, and keywords sections of each paper to evaluate whether any of the properties or their synonyms were mentioned. 


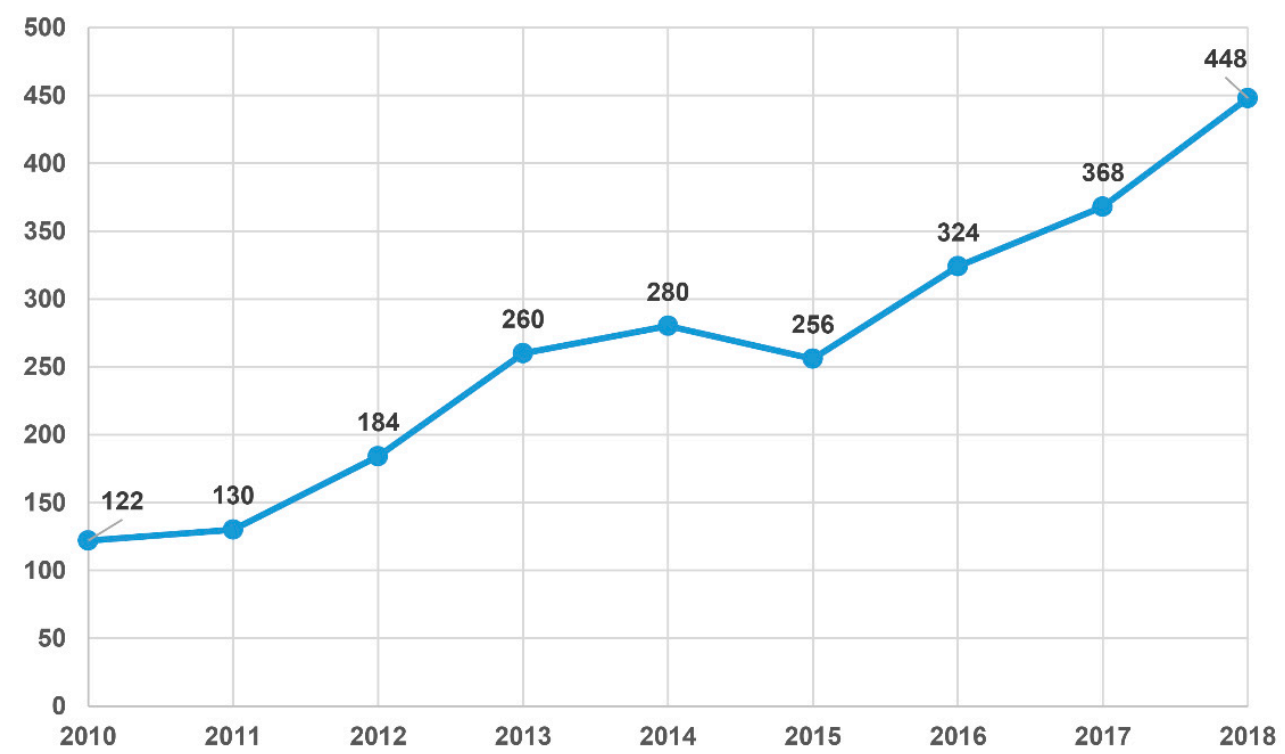

Figure 1. The trend of the total number of grey systems theory (GST) publications in field of socio-economic systems.

Following the elimination of the duplicates, the title, abstract, and keywords sections of each paper were analyzed. Out of a total of 2375 publications which were found through the search and corresponded to the inclusion criteria, the publications including four or more of the required properties were selected and further analyzed. Some of the papers proved to be false positive; that is, while they contained the appropriate properties, their content was not relevant to the topic. After the initial elimination of unrelated papers, a total of 396 papers remained for further processing. Following the final manual text screening, there were 147 full-length papers left for analysis. The set of articles for further processing from the manual and semi-automated search was finally reduced to 28 full-length papers, following the initial paper screening, which excluded papers not related to the topic of research (as described in Section 3.2 below).

\subsection{Data Extraction and Quality Evaluation}

The publications meeting the criteria were processed and for each publication, the following data were identified: author(s), year, the title of the study, objectives, methods, and main findings. In order to be eligible for analysis, the publications had to: (a) to be published after 2010; (b) focus on a social-economic problem; (c) focus on one of the sub-systems of social-economic systems; (d) discuss systems that are part of a larger social-economic system; (e) describe complex systems and a combination of economic and social issues; and (f) be written in the English language.

In contrast, a publication was excluded if it: (a) was written in a language other than English; (b) described a theoretical model or approaches to solutions instead of a practical and real problem (algorithms, mathematical models, statistical models); (c) focused on a technical description of the solution; (d) discussed specific solutions for a particular sector not directly relevant to social economic issues; (e) focused exclusively on an economic issue, regardless of social matters; (f) did not provide the full text; and (g) was a comment letter, report, or book chapter. Figure 2 schematically shows the process of publication search, selection, and analysis that was prepared based on RRISMA 2009 flow diagram [31]. 


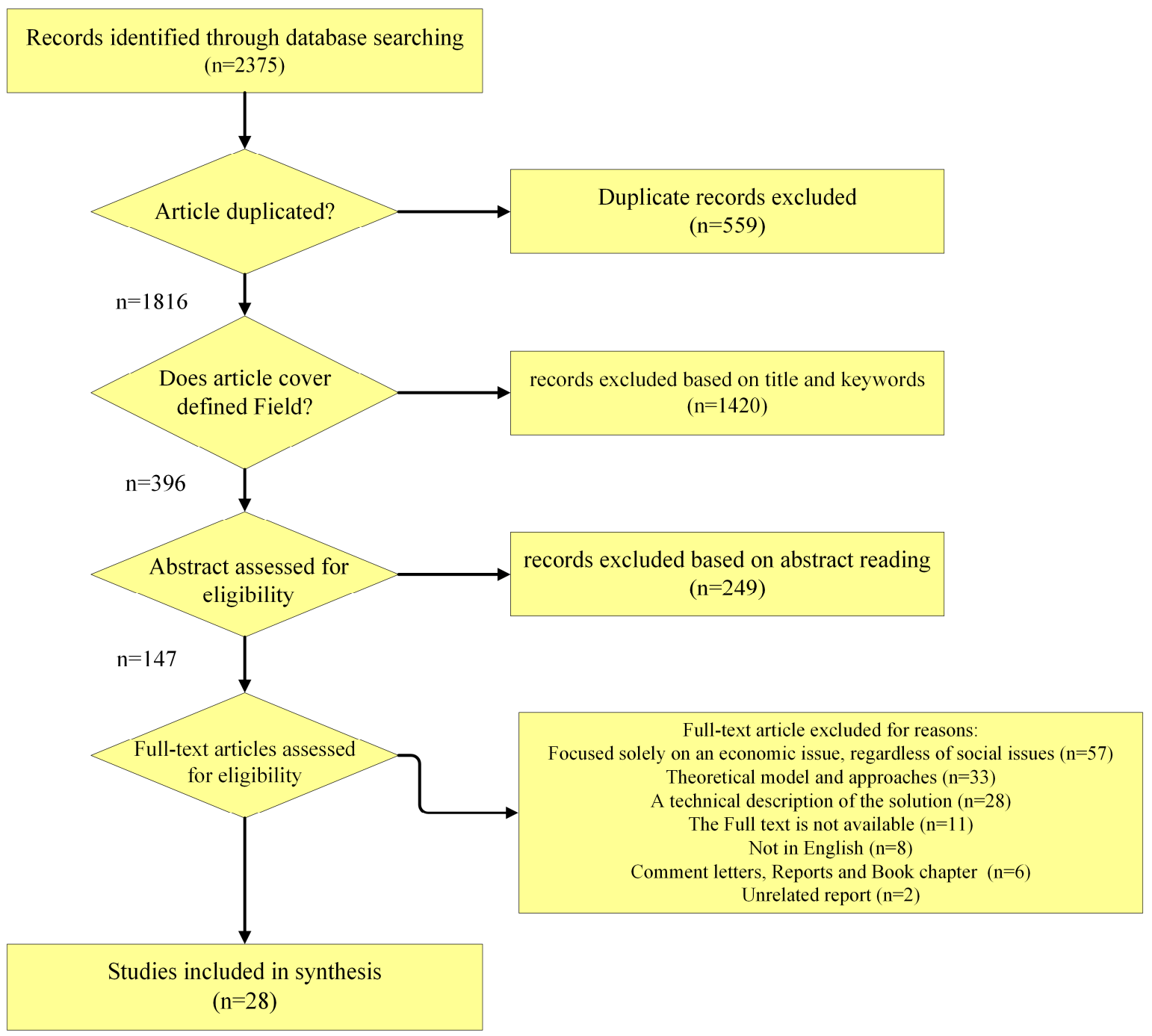

Figure 2. Publication search process based on RRISMA 2009 block diagram [31].

\section{Results}

The scoping review ultimately revealed that only 28 papers could be included for the analysis. Table 2 lists the papers and reports their focus according to the selected criteria, including the most discussed areas in the papers. The articles selected are sorted according to publication year. As Table 2 shows, most of the topics which the scholars chose to address were "social and cultural issues" including social responsibility, traffic problems, income inequality, domestic savings, crime, social awareness, and quality of life. Most of the articles dealing with social and cultural issues explored these issues along with another aspect of social and economic systems such as demographics, urbanization, development, and public sectors. Among the papers selected, ten papers investigated "social and cultural issues", out of which five ones focused on "social issues and urbanization" simultaneously. It seems that issues related to the public sector have also been taken into consideration by the researchers. Along with these, although some articles have addressed issues related to sustainability, but due to the scale and importance of the subject, this field still needs more work. 
Table 2. Aspects discussed in papers dealing with grey systems theory (GST) in the context of socio-economic systems.

\begin{tabular}{|c|c|c|c|c|c|c|c|c|c|c|c|c|c|}
\hline Papers (Authors, Year) & 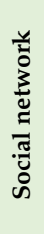 & 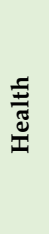 & 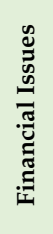 & 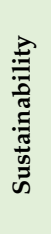 & 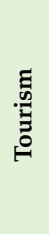 & 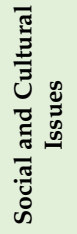 & 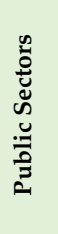 & 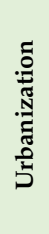 & 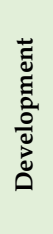 & 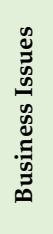 & 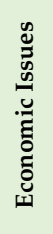 & 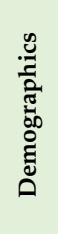 & 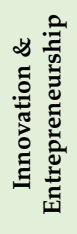 \\
\hline (Rahman et al., 2019) [32] & & $x$ & & & & & & & & & & & \\
\hline (Wey, 2019) [33] & & & & $x$ & & & $x$ & $x$ & & & & & \\
\hline (Zhang et al., 2018) [34] & & & & & & & & & & $x$ & & & \\
\hline (Shan et al., 2018) [35] & & & & & & & & & $x$ & & & & $x$ \\
\hline (Yu et al., 2018) [36] & & & & & & $\times$ & & & & & & $\times$ & \\
\hline (Wang et al., 2018) [37] & & & & & & $x$ & & $x$ & $x$ & & $x$ & & \\
\hline (Soni et al., 2017) [38] & & & & $x$ & & & $x$ & & & & & & \\
\hline (Eren \& Kaynak, 2017) [39] & & & & & & & & & $x$ & $x$ & & & \\
\hline (Duran et al., 2017) [28] & & & & & & $x$ & & & & & $x$ & & \\
\hline (Li et al., 2017) [40] & & & & & & $x$ & & $x$ & & & $x$ & & \\
\hline (Wang \& Nguyen, 2017) [41] & & & & & & & $x$ & & $x$ & & & & \\
\hline (Yu \& Fang, 2017) [13] & & & & & & $x$ & $x$ & & & & & & \\
\hline (Soni et al., 2017) [42] & & & & & & & $x$ & & & & & & \\
\hline (Delcea, 2016) [43] & $x$ & & & & & & & & & $x$ & & & \\
\hline (Li et al., 2016) [44] & & & $x$ & & & & & & & & & & \\
\hline (Mao et al., 2015) [45] & & & & & & & & & $x$ & & $x$ & & \\
\hline (Guo \& Zhang, 2015) [46] & $x$ & & & & & & & & & & & & \\
\hline (Zhang, 2014) [47] & & & $x$ & & & $x$ & & & & & & & \\
\hline (Li et al., 2014) [48] & & $x$ & & & & & $x$ & & & $x$ & & & \\
\hline (Wang \& Pei, 2014) [49] & & & & $x$ & $x$ & $x$ & & $x$ & & & & & \\
\hline (Wang et al., 2014) [23] & $x$ & & & & & & & & & & & & \\
\hline (Wang et al., 2012) [50] & & $x$ & & & & & $x$ & & & & & & \\
\hline (Huang, 2011) [51] & & $x$ & & & & $x$ & & & & & & & \\
\hline (Scarlat \& Delcea, 2011) [52] & & & $x$ & & & & & & & & & & \\
\hline (Liu et al., 2011) [53] & & & & & & & & $\times$ & $x$ & & & & \\
\hline (Kreng \& Yang, 2011) [54] & & $x$ & & & & & $\bar{x}$ & & & & & & \\
\hline (Yin et al., 2010) [55] & & & & & & $x$ & & $x$ & & & $x$ & & \\
\hline (Huang et al., 2010) [56] & & & & & & $x$ & & $x$ & $x$ & & & & \\
\hline
\end{tabular}

Wang et al. (2018) used GRA to investigate the relationship between gross domestic product (GDP), income elasticity, social awareness, the role of urbanization, and renewable energy development [37]. Viewed as a complex and grey system, the causal relationship between air pollution and social development was quantitatively analyzed in Li and colleagues' (2017) research. They relied on the grey relational model to present how the socio-economic and human activities affected the air pollution in urban areas [40]. Yin et al. (2010), pursuing a GRA, investigated socio-economic driving forces in an urban area. Their research tried to explore the deep dynamic mechanism of urban space expansion and to provide scientific support for its sustainable development [55].

Huang et al. (2010) tried to determine the main factors for a comprehensive analysis of urban thermo-effect. The six main factors of the urban thermo-effect were total size, GDP, the green area, the gross of freight, annual electricity consumption, and the population of the built-up area [56]. One of the papers selected in this field probed into public safety; Yu and Fang (2017) investigated and attempted to simulate the public safety dynamics of Shanghai using a set of collected indexes that described Shanghai's infrastructure and development, population, livability, crime, and disaster. In doing so, they applied a system dynamics modeling scheme and grey system simulation [13].

Guo and Zhang (2015) scrutinized the relationship among Turkey's macroeconomic indexes and domestic savings through GRA [46]. Yu et al. (2018) looked into the impact of population aging and industrial structure on $\mathrm{CO}_{2}$ emission trend prediction in China. Following "social and cultural issues", "developmental topics", was the second most frequently addressed topic in the selected papers, and it included such sub-topics as sustainable development, economic and social development, human development, tourism development, and urban development [36]. Shan et al. (2018) focused on recognizing the relationship and contribution of China's technological entrepreneurship to 
socio-economic development. They applied grey absolute correlation to assess the contributions of technological entrepreneurship to national development [35]. Eren and Kaynak (2017) evaluated EU-member states pursuant to human development and global competitiveness dimensions, using the multi-period GRA technique [39]. Mao et al. (2015) also explored the impact of research and development activities on GDP [45].

The areas of "urbanization" and "public sectors" were the next most frequently discussed categories in the studies under investigation. Evaluating e-governance efficacy, Soni et al. (2017) drew on the GST methodology to clarify the grey portions of e-governance [42]. Wang and Nguyen (2017) also focused on raising urban development quality based on the results of investors' efficient performance evaluation. Sustainability was another important issue in socio-economic systems in some of the papers [41]. Soni et al. (2017) explored the grey-based model for energy security analysis, trying to achieve sustainability; the study assumed that the model could help draw a rough trajectory of strategies contributing to energy security [38]. In addition, sustainable urban development has been introduced as an appropriate solution to address multiple urbanization problems such as congestion, serious air pollution, endless urban sprawl, and inappropriate land development with low urban density. This has led to the emergence of three innovative growth structures: smart growth, sustainable growth, and inclusive growth. Many researchers confidently claim that sustainable urban development improves the quality of life. For this reason, Wey (2019) tried to constructing urban dynamic transportation planning strategies for improving quality of life and urban sustainability under emerging growth management principles, using a grey forecasting model [33].

Wang and Pei (2014) addressed urban tourism sustainability, relying on a grey comprehensive evaluation method. They assumed the method could help tourism management departments in their policy making. Their research focused on a combination of topics related to urbanization, tourism, sustainability, and social responsibility [49]. Liu et al. (2011) investigated sustainable development and urbanization, employing an integrated sustainable development method to modeling and analyzing the eco-environmental effects of urbanization [53].

Analyzing healthcare systems was another topic of interest in the papers relying on grey theories. Rahman et al. (2019) utilized a grey approach to predicting healthcare performances [32]. Huang (2011) described the application of GST in telecare and the analysis of life quality [51]. Li et al. (2014) presented a theoretical and empirical analysis of supplier-induced demand in the healthcare market [48]. Wang et al. (2012) also evaluated and made an early warning prediction, using grey prediction models for improving the food security status and public health [50]. Since an ideal resource allocation in health care for ensuring people to access equal health care services is a very important issue, Kreng and Yang (2011) used grey incidence analysis to investigating about the equality of resource allocation in health care under the National Health Insurance System in Taiwan [54]. Some researchers contended that GST could contribute to the analysis of social networks. Delcea (2016) explored the impact of social media engagement on customers' decisions, through a grey analysis [43]. Duran et al. (2017) also tried to detect communities in social networks, relying on GRA [28]. Similarly, Wang et al. (2014) utilized a grey Verhulst model to predict trending topics on the Internet [23].

Another area of GST-based research focused on financial issues in the light of social matters. In the selected papers, Li et al. (2016) used grey fuzzy comprehensive model to evaluate regional financial innovation [44]. Zhang (2014) made use of grey incidence analysis to examine the effects of financial deepening on income inequality, while combining financial issues with social problems [47]. Scarlat and Delcea (2011) analyzed the bankruptcy syndrome using GST [52].

Table 3 reports a detailed description of the topic of each paper (including objectives, methods and main findings), especially in the light of their main findings. As Table 3 suggest, GRA and its derivative methods were the most commonly used method for analyzing the topics. The other methods used in the selected papers to analyze socio-economic issues were grey correlation models, grey prediction models, grey game models, grey decision-making models, grey incidence analysis, grey system simulation, grey Verhulst model, and finally grey control systems method (referred to only in one article). 
Table 3. Summary of studies.

\begin{tabular}{|c|c|c|c|}
\hline Papers Title & Objectives & Methods & Main Findings \\
\hline $\begin{array}{l}\text { A grey approach to predicting healthcare } \\
\text { performance [32] }\end{array}$ & $\begin{array}{l}\text { Analyzing and predict the indicators of } \\
\text { healthcare }\end{array}$ & Grey prediction model & $\begin{array}{c}\text { Provide the information for evaluating and predicting the } \\
\text { performance of a hospital }\end{array}$ \\
\hline $\begin{array}{l}\text { Constructing urban dynamic transportation } \\
\text { planning strategies for improving quality of } \\
\text { life and urban sustainability under emerging } \\
\text { growth management principles [33] }\end{array}$ & $\begin{array}{l}\text { the urban transportation planning strategy } \\
\text { and its dynamics }\end{array}$ & Grey forecasting & $\begin{array}{l}\text { proposing an integrated approach to identify the most important } \\
\text { criteria that can signify alternative sustainable urban } \\
\text { transportation planning strategies }\end{array}$ \\
\hline $\begin{array}{l}\text { Grey game research about customer } \\
\text { preference, international competition and } \\
\text { the choice of industrial type [34] }\end{array}$ & $\begin{array}{l}\text { Discussing how domestic firms compete } \\
\text { with the multinational company based on } \\
\text { consumer's preferences }\end{array}$ & Grey game model & $\begin{array}{l}\text { Consumers prefer domestic products, and with the improvement } \\
\text { of technological level, this preference grows stronger }\end{array}$ \\
\hline $\begin{array}{l}\text { Assessing relationship and contribution of } \\
\text { China's technological entrepreneurship to } \\
\text { socio-economic development [35] }\end{array}$ & $\begin{array}{l}\text { Studying technological entrepreneurship } \\
\text { from macro perspectives for socio-economic } \\
\text { development }\end{array}$ & $\begin{array}{l}\text { Grey absolute } \\
\text { correlation }\end{array}$ & $\begin{array}{l}\text { There is a high correlation between technological } \\
\text { entrepreneurship and economic growth }\end{array}$ \\
\hline $\begin{array}{l}\text { Impact of population aging and industrial } \\
\text { structure on CO2 emissions and emissions } \\
\text { trend prediction in China [36] }\end{array}$ & $\begin{array}{l}\text { Analyzing the status of demographic and } \\
\text { industrial structure, the impact factors of } \\
\text { CO2 emissions }\end{array}$ & $\mathrm{GM}(1,1)$ & $\begin{array}{l}\text { Population aging, industrial structure and per-capita wealth have } \\
\text { a positive impact on } \mathrm{CO} 2 \text { emissions growth. }\end{array}$ \\
\hline $\begin{array}{l}\text { How does hydrogen-based renewable } \\
\text { energy change with economic development? } \\
\text { Empirical evidence from } 32 \text { countries [37] }\end{array}$ & $\begin{array}{l}\text { Analyzing the drivers promoting } \\
\text { hydrogen-based renewable energy } \\
\text { utilization }\end{array}$ & GRA & $\begin{array}{l}\text { GDP per capita is a positive contributor to renewable energy } \\
\text { consumption, social awareness about climate change and energy } \\
\text { security is not enough to motivate the switch from traditional to } \\
\text { renewable energy sources }\end{array}$ \\
\hline $\begin{array}{l}\text { Enlightening grey portions of energy } \\
\text { security towards sustainability [38] }\end{array}$ & $\begin{array}{c}\text { Determining priority order of energy sector } \\
\text { projects on investments and strategic } \\
\text { dimensions }\end{array}$ & Grey Decision & $\begin{array}{l}\text { Solar projects get high-priority order and renewable energy } \\
\text { projects are preferred over the conventional projects such as coal } \\
\text { and gas }\end{array}$ \\
\hline $\begin{array}{l}\text { An evaluation of EU member states } \\
\text { according to human development and global } \\
\text { competitiveness dimensions using the } \\
\text { multi-period grey relational analysis } \\
\text { technique [39] }\end{array}$ & $\begin{array}{l}\text { Investigating the multi-period, } \\
\text { multi-attribute decision making problems }\end{array}$ & GRA & $\begin{array}{l}\text { The general ranking of EU member states has been provided in } \\
\text { intervals of certain time periods called decision units. }\end{array}$ \\
\hline $\begin{array}{c}\text { Grey relational analysis between Turkey's } \\
\text { macroeconomic indicators and domestic } \\
\text { savings [28] }\end{array}$ & $\begin{array}{l}\text { Analyzing the degree of relationship } \\
\text { between domestic savings and } \\
\text { macroeconomic indicators }\end{array}$ & GRA & $\begin{array}{c}\text { Current balance ratio and GDP growth are ascertained as } \\
\text { indicators which have a high degree of relationship with } \\
\text { domestic savings. }\end{array}$ \\
\hline $\begin{array}{l}\text { Influence of Social-economic Activities on } \\
\text { Air Pollutants in Beijing, China [40] }\end{array}$ & $\begin{array}{l}\text { Analyzing the causal relationship between } \\
\text { the social development and the air pollution } \\
\text { and the socio-economic effects and human } \\
\text { activities on it }\end{array}$ & GRA & $\begin{array}{l}\text { the air pollution present in general moderate correlations with } \\
\text { most of the socioeconomic variables. }\end{array}$ \\
\hline $\begin{array}{c}\text { Enhancing Urban Development Quality } \\
\text { Based on the Results of Appraising Efficient } \\
\text { Performance of Investors-A Case Study in } \\
\text { Vietnam [41] }\end{array}$ & $\begin{array}{l}\text { Assessing the investment effectiveness of } \\
\text { leading corporations in the field of urban } \\
\text { development and infrastructure investment }\end{array}$ & Grey forecasting & $\begin{array}{l}\text { the method help for long-term vision, and practical efficiency to } \\
\text { quickly meet the needs of urban development plans }\end{array}$ \\
\hline
\end{tabular}


Table 3. Cont.

\begin{tabular}{|c|c|c|c|}
\hline Papers Title & Objectives & Methods & Main Findings \\
\hline $\begin{array}{l}\text { The dynamics of public safety in cities: A } \\
\text { case study of Shanghai from } 2010 \text { to } 2025 \text { [13] }\end{array}$ & $\begin{array}{l}\text { Simulating the public safety dynamics with } \\
\text { a set of indicators }\end{array}$ & $\begin{array}{l}\text { Grey system } \\
\text { simulation }\end{array}$ & $\begin{array}{c}\text { public safety is increasing due to a high level of urban } \\
\text { socioeconomic development, which provides a foundation for } \\
\text { urban public safety. }\end{array}$ \\
\hline Digitizing grey portions of e-governance [42] & $\begin{array}{l}\text { Assessing e-governance efficacy in various } \\
\text { sectors and enlightening grey portions of } \\
\text { e-governance }\end{array}$ & $\begin{array}{l}\text { GST-based (COPRAS) } \\
\text { method }\end{array}$ & $\begin{array}{l}\text { Implementation of ICT applications for e-governance should be } \\
\text { in the sectors such as environment, climate change, the railways } \\
\text { and Industrial sector. }\end{array}$ \\
\hline Grey social media engagement analysis [43] & $\begin{array}{c}\text { Discussing the customers relationship with } \\
\text { the companies and the social media } \\
\text { engagement }\end{array}$ & $\begin{array}{l}\text { Grey incidence } \\
\text { analysis, GRA }\end{array}$ & $\begin{array}{l}\text { A strong relationship between the decision easiness and both } \\
\text { time spent on social media platforms and number of the } \\
\text { accessed websites }\end{array}$ \\
\hline $\begin{array}{l}\text { Grey fuzzy comprehensive evaluation of } \\
\text { regional financial innovation ability based } \\
\text { on two types weights [44] }\end{array}$ & $\begin{array}{l}\text { Evaluating the regional financial } \\
\text { innovation ability }\end{array}$ & Grey fuzzy evaluation & $\begin{array}{c}\text { Development of regional financial innovation is not balanced and } \\
\text { having obvious spatial clustering feature }\end{array}$ \\
\hline $\begin{array}{l}\text { The impact of R\&D on GDP study based on } \\
\text { grey delay Lotka-Volterra model [45] }\end{array}$ & $\begin{array}{l}\text { Elevating the accuracy when predicting the } \\
\text { GDP on R\&D }\end{array}$ & $\begin{array}{c}\text { Grey delay } \\
\text { Lotka-Volterra }\end{array}$ & $\begin{array}{l}\text { The delay between R\&D and GDP was } 2.625 \text { years and it would } \\
\text { gradually be reduced with the economy increasing }\end{array}$ \\
\hline $\begin{array}{l}\text { Detecting communities in social networks by } \\
\text { local affinity propagation with grey } \\
\text { relational analysis [46] }\end{array}$ & $\begin{array}{l}\text { Discovering social communities from the } \\
\text { social networks }\end{array}$ & GRA & $\begin{array}{l}\text { The experimental results prove the proposed algorithm to be } \\
\text { quite effective and efficient at community discovery. }\end{array}$ \\
\hline $\begin{array}{l}\text { The effects of financial deepening on income } \\
\text { inequality based on grey incidence analysis: } \\
\text { Empirical evidence from China [47] }\end{array}$ & $\begin{array}{l}\text { Clarifying the relationship between income } \\
\text { inequality and financial deepening }\end{array}$ & $\begin{array}{l}\text { Grey incidence } \\
\text { analysis }\end{array}$ & $\begin{array}{l}\text { The development of credit market does not have a strong } \\
\text { relationship with the growth of income and income inequality }\end{array}$ \\
\hline $\begin{array}{l}\text { Theoretical and empirical analysis of the } \\
\text { supplier induced demand in health care } \\
\text { market in China [48] }\end{array}$ & $\begin{array}{l}\text { Providing theoretical model about } \\
\text { supplier-induced demand (SID) in health } \\
\text { care market }\end{array}$ & $\begin{array}{l}\text { Grey control systems, } \\
\text { Grey game }\end{array}$ & $\begin{array}{l}\text { It is the reduction of government finance to hospital that is the } \\
\text { long-term steady determinants of growth of } \\
\text { healthcare expenditure }\end{array}$ \\
\hline $\begin{array}{l}\text { A systems thinking-based grey model for } \\
\text { sustainability evaluation of urban } \\
\text { tourism [49] }\end{array}$ & $\begin{array}{l}\text { Analyzing the sustainability of } \\
\text { urban tourism }\end{array}$ & $\begin{array}{l}\text { Grey correlation } \\
\text { analysis }\end{array}$ & $\begin{array}{l}\text { The social responsibility fulfillment of urban tourism in five cities } \\
\text { fails to reach a satisfactory level }\end{array}$ \\
\hline $\begin{array}{l}\text { Grey SystemTheory based prediction for } \\
\text { topic trend on Internet [23] }\end{array}$ & $\begin{array}{l}\text { Presenting an algorithm to predict } \\
\text { topics trend }\end{array}$ & Grey Verhulst Model & $\begin{array}{l}\text { Predicting topics trend and solving the problem with a } \\
\text { high accuracy }\end{array}$ \\
\hline $\begin{array}{l}\text { Grey prediction model-based food security } \\
\text { early warning prediction [50] }\end{array}$ & evaluating and early warning prediction & Grey prediction & more attention should be paid to the food security situation \\
\hline $\begin{array}{l}\text { Application of grey system theory in } \\
\text { telecare [51] }\end{array}$ & $\begin{array}{l}\text { Discussing older adult users' opinions on the } \\
\text { telecare and its effect on their QOL }\end{array}$ & GRA & $\begin{array}{l}\text { The living quality has the greatest effect on the perceived effects } \\
\text { of the telecare }\end{array}$ \\
\hline
\end{tabular}


Table 3. Cont.

\begin{tabular}{cccc}
\hline Papers Title & Objectives & Methods & Main Findings \\
\hline $\begin{array}{c}\text { Complete analysis of bankruptcy syndrome } \\
\text { using grey systems theory [52] }\end{array}$ & $\begin{array}{c}\text { Analyzing the company level for shaping the } \\
\text { relations among variables }\end{array}$ & GM(0, N) & $\begin{array}{c}\text { the diagnosis of the company can show the main elements that } \\
\text { are affecting a company's activity }\end{array}$ \\
\hline $\begin{array}{c}\text { An integrated sustainable development } \\
\text { approach to modeling the eco-environmental } \\
\text { effects from urbanization [53] }\end{array}$ & $\begin{array}{c}\text { Presenting relationships between } \\
\text { urbanization and Eco environment and } \\
\text { sustainable development }\end{array}$ & $\begin{array}{c}\text { Grey relative } \\
\text { technique }\end{array}$ & $\begin{array}{c}\text { The urbanization sustainability may be met on condition that } \\
\text { either populated urbanization or social urbanization pattern } \\
\text { is adopted }\end{array}$ \\
\hline $\begin{array}{c}\text { The equality of resource allocation in health } \\
\text { care under the National Health Insurance } \\
\text { System in Taiwan [54] }\end{array}$ & $\begin{array}{c}\text { An ideal resource allocation in health care } \\
\text { for ensuring most people to access equal } \\
\text { health care services }\end{array}$ & $\begin{array}{c}\text { Grey incidence } \\
\text { analysis }\end{array}$ & Measuring resource allocation of health care services in Taiwan \\
\hline $\begin{array}{c}\text { Analysis of socio-economic driving forces on } \\
\text { built-up area expansion in Xiamen [55] }\end{array}$ & $\begin{array}{c}\text { Exploring the deep dynamic mechanism of } \\
\text { urban space expansion and its sustainable } \\
\text { development }\end{array}$ & GRA & $\begin{array}{c}\text { Resource consumption factors and population factors have had a } \\
\text { significant driving effect on the expansion of built-up area }\end{array}$ \\
\hline $\begin{array}{c}\text { Urban climate change: A comprehensive } \\
\text { ecological analysis of the thermo-effects of } \\
\text { major Chinese cities [56] }\end{array}$ & $\begin{array}{c}\text { Computing the urban thermo-effect } \\
\text { of summer }\end{array}$ & $\begin{array}{c}\text { Grey correlation } \\
\text { analysis }\end{array}$ & $\begin{array}{c}\text { The six factors of the urban thermo-effect are the total size, GDP, } \\
\text { the green area, the population of the built-up area, the gross of } \\
\text { freight and annual electricity consumption }\end{array}$ \\
\hline
\end{tabular}




\section{Discussion}

Without a doubt, social and economic systems are complex entities. This complexity affects all subsystems and related fields in these systems. Increased complexity could lead to greater uncertainty; to address this considerable degree of ambiguity, one must acknowledge the function of uncertainty-based theories and methods. In addition, the analysis needs to collect relevant available data. Complexity, uncertainty, and the lack of access to a large collection of data have led researchers to analyze socio-economic systems through GST-based methods, because such methods can analyze and solve problems with limited information. Additionally, GST-based methods are more advanced in terms of efficiency compared to other methods of decision-making and analysis.

Soni et al. (2017) acknowledged that in information and communication technology (ICT), for example in an e-governance project, a complex and uncertain environment is a natural condition. Conducting the operations into the development of the respective segments in the ICT-based governance projects includes a high scale of complexity. GST-based decision-making methods are capable of detecting and addressing breaches of information security, while developing ICT applications and the e-governance process. GST-based applications can bring about helpful methods for capturing the pessimistic, optimistic, and realistic snap shots of e-governance. GST provides a scenario between black and white numbers, and the ranking obtained by GST versions is more precise in nature, as it captures the greyness of e-governance [42].

Generally, GST-based methods can achieve better results over time in online social networks because the nature of the relationships generated in online social networks is characterized by incomplete information [43]. Since the social networks are generally very large, the near-linear time and space complexity is quite important for their analysis. Guo and Zhang (2015) applied the GRA to solve the complex relations among members of social networks. Instead of the widely used Euclidean distance, they adopted the grey relational degree in the calculation of node similarity, because it is more proper for the detection of the hidden relations among the nodes. Their GST-based algorithm improved both time and space complexity [46]. They explained that, to handle complex structures in social networks, GRA was very suitable for the calculation of similarity between the data nodes. Comprehensive experiments conducted on both real-world social networks and artificial networks proved the effectiveness and efficiency of the GST-based algorithm [46]. Wang et al. (2014) showed that errors and other statistical information between in the grey Verhulst model were less than in other classical models and the forecasting performance of GM-related predicting tools was better than that of many common methods. It is, thus, a valuable method to real world applications for the forecast of topic trends on the Internet [23].

Urban areas, too, are types of complex socio-economic and natural ecological systems. In a sense, the interactive coupling system of urbanization and the environment can be considered a complex and grey system with incomplete information. We cannot simply use correlation analysis to study the interactive relations between each element of the system, because it cannot accurately evaluate these relations to an acceptable degree. Drawing on the social-economic-natural complex ecosystem theory, Huang et al. (2010) listed as many factors as possible, including social, economic, and natural ones, which could affect the urban thermo-effect. They conducted a grey correlation analysis of the 22 indicators selected through the following processes: data standardization, calculation of grey correlation coefficients between different indicators, and calculation of their grey correlation degree. They proved that the GST-based system significantly increased the ability to analyze [56].

The grey comprehensive evaluation model can effectively convert complex indices into comprehensive optimal membership degrees, which are easy to understand. It can be used in evaluating many complex systems. Wang and Pei (2014) have used it to evaluate the sustainability of urban tourism. The evaluation of the sustainable development of urban tourism is a complex system containing multiple elements such as tourism resources, society and economy, environment, management, etc. [49]. Also, Wey (2019) objectively showed that the role and positioning of the grey prediction model is to provide scientific and correct prediction information to approach a more realistic 
and dynamic situation in constructing urban dynamic transportation planning strategies for improving quality of life and urban sustainability. Especially, when the problem is under the constraints of a small number of samples or a small number of surveys [33].

Air pollution constructed by social economic activities is a multifactor system in adaptation with grey specifications. Li et al. (2017) used the GRA to find the interaction correlation between social economic factors and air pollution. They observed that the GRA could help to explore the association of air pollution with socioeconomic characteristics and could derive the specific management plans for air pollution in an urban system [40]. They explained that the integrated influence of many factors is crucial to the subsequent development of a dynamic system model. Under the condition of incomplete information, small sample data, and a lack of experience, GRA could be used as a method to address questions like: What are the major factors? What are the minor factors? Which factors may contribute to or break the progress? And, what are the factors that leave a prominent impact on the dynamic system? GRA get the better of the drawbacks of multivariable regression analysis and the stochastic process methods [40].

The energy sector is another field characterized by a high degree of complexity. Soni et al. (2017) asserted that the grey decision theory-based method can accurately address energy security problems considering different scenarios of energy supply. They noticed that there were some advantages in GST over the fuzzy system theory and the net present value method. They also found that GST could be flexible in the case of uncertain/fuzzy situations, and it could support priority-based investment for the sub-sectors, while helping decision-makers to increase sustainability in the energy sector and enhance energy security [38].

Soni et al. (2017) further claimed that it would be necessary to make efforts to handle complexity through GST-based applications in terms of energy planning, foreign direct investment, research and development (R\&D), and innovation [38]. In addition, GRA can help explore the relationships, at a national level, between renewable energy development and its affective factors. The panel estimators and GRA in the field of renewable energy development can help to: (a) explain the commitment to renewables as a time series; (b) analyze the motives for renewable energy development; (c) summarize experiences from both developing and advanced nations; and (d) explore the relational degrees between renewable energy use and its motives.

Generally speaking, GRA can provide preliminary directions for renewable energy development and feedback on the effect of its drivers (e.g., the correlation between climate change and renewable energy use) [37]. System dynamic modeling plans mostly suffer from comparative rigidity when relationships between various variables must be determined confirmatively from the data, which is a problem that could potentially limit the model's applicability. This situation especially occurs when the data consist of a relatively short temporal series and some data items are quite occasionally recorded or fluctuate drastically, which is frequently the case in socio-economic systems. The results showed that combining the grey system simulation methods into system dynamics simulation helps the system analysts to make better decisions because it provide more rational simulation results [13].

Because all activities taking place in a company run in an uncertain and a continually changing environment, GST seems to better shape the relations between the variables. The incidence relationships between a system's factors (as in the case of a company's performance), as well as the causal relationships between them, can be formulated through the grey economic-financial knowledge matrix, as a GST-based mathematical model, that can model and predict future stages in a system's evolution. The grey economic-financial knowledge matrix can help the analyst in the process of deciding the strength of the link between each cause and effect association (whether it refers to financial or non-financial performance). In the analysis directed by Scarlat and Delcea (2011), at the firm level, the GM models demonstrated to be successful [52].

GRA is an easy and efficient factor analysis method for examining the internal relevancy of a system and offers reference information for constructing a complex system model because it uses connections as guideline and multi-angle thinking as a fundamental feature. When making grey 
relational decisions, the development between the characteristic sequence and behavior sequence of the system may not be synchronized. The development of the characteristic sequence may lag behind the behavior sequence. Such a nonsynchronous phenomenon is called delay. There are many delay phenomena in a socio-economic system and it is a common situation in various field of these systems. In these systems, unlike many mechanical systems, you do not immediately figure out the result of your actions and decisions. For example, investment does not generate revenue immediately; it often needs to wait for a period of time. There is also delay in GDP and R\&D relationship. The development of GDP usually lags behind that of R\&D. Grey delay relation analysis can help us estimate delay time. Mao et al. (2015) presented a grey delay Lotka-Volterra model for investigating the impact of R\&D on GDP. Compared with the real values, the GST-based model showed only an approximate $10 \%$ prediction error [45].

Furthermore, GRA solves multiple-criteria decision-making (MCDM) problems by merging the entire range of performance attribute values for every alternative into one single value. This decreases the original problem to a single attribute decision-making problem. Two GRA dimensions, which establish a major part of GST, can be utilized: first, a nonparametric measure of the correlation between the sequences, such as a statistical analysis; second, a correlation between the sequences by creating a reference sequence from the best values of comparable sequences. Hence, according to the obtained relationship outcomes, the comparable sequences can be sorted from the best value to the worst value, like the functioning of MCDM techniques [39].

Furthermore, the evaluation indicator system of regional financial innovation constitutes a multi-objective and multi-layer decision-making system, but how to determine suitable weights represents a key problem. It can be considered a grey and complex socio-economic problem. There are many methods to determine index weights, such as the subjective determination method, the objective setting method, and the combined fixed weight method. Yet, confirming weights, as a measure of grey uncertainty, will be inevitably influenced by subjective factors. Because the index weight value is $[0,1]$, and we often do not know its exact value, the index weight may be regarded as a grey number. It seems that the traditional decision approach cannot obtain the classification value and weighted integrated value at the same time, but the multi-objective and multi-layer grey-fuzzy decision-making model with feedback can overcome the limitations [44].

Duran et al. (2017) used GRA to investigate Turkey's macroeconomic indexes and domestic savings causality [28]. They expressed that GRA could generate meaningful results against a small volume of data, thus making it possible to achieve accurate results. This is a great advantage for grey approaches that create conditions for obtaining more accurate results with less information. Another advantage of using GRA in this field is that the handled indicators are subject to a weighting process. This way, it is ensured that if an indicator involves a high level of information within a certain period, it experiences a higher degree of relation within the in question. This additional calculation makes the results more reliable [28]. Moreover, GRA is a highly beneficial approach, because it can make use of relatively small data collections and does not demand strict compliance to certain statistical laws, or simple or linear relationships among the observable variables. Thus, it can overcome the bugs of statistical methods.

The results also indicated that GST was a feasible and effective analysis method for investigating healthcare systems because health systems can be considered complex and grey socio-economic systems [51]. Rahman et al. (2019) argued that although moving average, exponential smoothing, and linear regression are the most popular methods for implementing a time series forecasting model, it is evident that the $\operatorname{GM}(1,1)$ model involves a much lower percentage of error than linear regression approaches; also data fitting in the $\operatorname{GM}(1,1)$ model is higher because of the higher coefficient of the correlations [32]. They expressed that a successful implementation of both the $\operatorname{GM}(1,1)$ model and linear regression model showed that the grey-based predictive model was reliable and efficient. Moreover, one of the main advantages of the grey prediction model is that is does not depend on system data or how the data are generated. When the sample size is comparatively small, the $\operatorname{GM}(1,1)$ 
model is more effective than other existing predicting models. In modern healthcare management systems, data analytics is gaining prominence among decision-makers. The selection of input data is very important in obtaining usable output. Therefore, the grey model can help to find better analysis results [32].

Accordingly, the study of Kreng and Yang (2011), utilizing cross-sectional data, proposed a multi-criteria decision-making approach with grey incidence analysis to measure horizontal equity of health care resource allocation in Taiwan. They believed that Grey incidence emphasizes in choosing an ideal resource allocation in a system whether system is known or not, means the uncertain relation between the things or the uncertain relation among systemic factors to the main behavior. It is a simple and particular systemic analytic method, overcomes the limitations of traditional mathematical statistics methods such as the necessity of overlarge samples, a great deal of calculation, and the disaccord between quantitative result and qualitative analysis [54].

Contrasted to other statistical methods, grey incidence analysis, which is a momentous part of GST, provides a new approach for analyzing systems, and it can be applied whether there is adequate data distribution or adequate sample size. Even more advantageous is the small volume of computations involved which can be carried out conveniently without any discrepancy between quantitative and qualitative conclusions. Following these postulates, Zhang (2014) applied grey incidence analysis to compute the degree of grey incidence between some socio-economic indicators. The need for less information, as well as more accurate results, illustrates the advantage of the method chosen in this research. Dependent variables included per capita net income of rural residents, per capita disposable income of urban residents and overall Theil Inequality Index for China. Independent variables also included depth of direct financing, depth of credit, and depth of insurance [47].

According to the results of this scoping review, while GST has had a rapid and satisfactory growth in analyzing socio-economic systems, it is not yet widely utilized when we consider the expansive breadth of issues in social-economic systems; scholars, then, should pay particular attention to the use of GST in analyzing socio-economic systems. Because of the incomplete information in socio-economic systems and their complexity, these systems appear grey to us, which is a condition that highlights the importance of considering uncertainty in estimations, calculations, solution methods, and decision-making processes. Dealing with these issues without the ubiquitous problem of uncertainty is a tactical mistake in finding appropriate solutions. Indeterminate systems and issues must be analyzed according to methods that take into account uncertainty and human imperfect perception.

\section{Conclusions}

This study explored a diversity of GST-based socio-economic systems and the relevant areas addressed in the literature, using a scoping review method. Of course, many studies showed a lack of coherent and systematic views of the topic in question. Most of the studies exclusively examined the relationship between the variables or decisions, regardless of the systems thinking, although this factor shapes the basis of GST. The authors typically focused on one aspect of social and economic implications and tried to examine it substantially. Yet, systematic viewpoints, holistic thinking, causal circles, cause and effect loops, feedback loops, and systematic cycles were rarely addressed in the articles published in this area and were often overlooked.

However, as it seems, using holistic approaches and GTS-based systems thinking methods could help achieve better results in analyzing socio-economic systems. Grey control field and its related methods can be a very attractive, practical, and appropriate method for solving social and economic issues which are often ignored.

Author Contributions: Supervision, Methodology and Editing: S.L.; Data and Sources Searching, Writing-Original Draft Preparation, Writing-Review: E.J.; Conceptualization and Visualization: E.J. and S.L.

Funding: This work was supported by a project of the National Natural Science Foundation of China (71671091), a Marie Curie International Incoming Fellowship under the 7th Framework Programme of the European Union entitled "Grey Systems and Its Application to Data Mining and Decision Support" (Grant No. 629051). It is 
also supported by a joint project of both the NSFC and the RS of the UK entitled "On grey dynamic scheduling model of complex product based on sensing information of internet of things" (71811530338), a project of the Leverhulme Trust International Network entitled "Grey Systems and Its Applications" (IN-2014-020), and a project of China Postdoctoral Science Foundation(2018M642254). Also, the authors would like to acknowledge the support provided by the Postdoctoral Foundation of Nanjing University of Aeronautics and Astronautics.

Conflicts of Interest: The authors declare no conflict of interest.

\section{References}

1. Mele, C.; Pels, J.; Polese, F. A Brief Review of Systems Theories and Their Managerial Applications. Serv. Sci. 2010, 2, 126-135. [CrossRef]

2. Rousseau, D. Systems Philosophy and the Unity of Knowledge: Systems Philosophy and the Unity of Knowledge. Syst. Res. 2014, 31, 146-159. [CrossRef]

3. Belle, H. Perspectives on the World: An Interdisciplinary Reflection; Worldviews Group, Ed.; VUB Press, Distributed by Paul Company Publishers Consortium: Brussels, Belgium, 1995; ISBN 978-90-5487-113-2.

4. Shaked, H.; Schechter, C. Definitions and Development of Systems Thinking. In Systems Thinking for School Leaders; Springer International Publishing: Cham, Switzerland, 2017; pp. 9-22, ISBN 978-3-319-53570-8.

5. Rousseau, D.; Wilby, J.; Billingham, J.; Blachfellner, S. Translational Systems Sciences. In General Systemology Transdisciplinarity for Discovery, Insight and Innovation; Springer: Singapore, 2018; ISBN 978-981-10-0891-7.

6. Liu, S.; Lin, Y. Grey Systems: Theory and Applications (Understanding Complex Systems); Springer: Berlin, Germany, 2010; ISBN 978-3-642-16158-2.

7. Parsons, T. Routledge sociology classics. In The Social System, New, ed.; Routledge: London, UK, 1991; ISBN 978-0-415-06055-4.

8. Boulding, K.E. General Systems Theory-The Skeleton of Science. Manag. Sci. 1956, 2, 197-208. [CrossRef]

9. Clark, R.L. Ageing Populations. In Social Economics; Eatwell, J., Milgate, M., Newman, P., Eds.; The New Palgrave; Palgrave Macmillan: London, UK, 1989; pp. 1-3, ISBN 978-1-349-19806-1.

10. Kapliński, O.; Peldschus, F. Socio-economic systems: A school of professor Romualdas Ginevicius. Bud. I Inżynieria Środowiska 2011, 2, 517-520.

11. Liu, S.; Yang, Y.; Forrest, J. Computational Risk Management. In Grey Data Analysis Methods, Models and Applications; Springer: Singapore, 2017; ISBN 978-981-10-1840-4.

12. Ju-Long, D. Control problems of grey systems. Syst. Control Lett. 1982, 1, 288-294. [CrossRef]

13. Yu, D.; Fang, C. The dynamics of public safety in cities: A case study of Shanghai from 2010 to 2025. Habitat Int. 2017, 69, 104-113. [CrossRef]

14. Liu, S.; Lin, C.; Yang, Y. Several problems need to be studied in grey system theory. In Proceedings of the 2017 International Conference on Grey Systems and Intelligent Services (GSIS), Stockholm, Sweden, 8-11 August 2017.

15. Liu, S.; Yang, Y.; Xie, N.; Forrest, J. New progress of Grey System Theory in the new millennium. Grey Syst. Theory Appl. 2016, 6, 2-31. [CrossRef]

16. Deng, J.L. Introduction to Grey System Theory. J. Grey Syst. 1989, 1, 1-24.

17. Lu, M.; Wevers, K. Grey System Theory and Applications: A Way Forward. J. Grey Syst. 2007, 10, 47-53.

18. Sterman, J.; Sterman, J.D. Business Dynamics: Systems Thinking and Modeling for a Complex World with CD-ROM, HAR/CDR ed.; McGraw-Hill Education: Boston, MA, USA, 2000; ISBN 978-0-07-238915-9.

19. Li, Q.; Lin, Y. Review paper: A Briefing to Grey Systems Theory. J. Syst. Sci. Inf. 2014, 2, 178-192. [CrossRef]

20. Javanmardi, E.; Liu, S. Exploring the Human Cognitive Capacity in Understanding Systems: A Grey Systems Theory Perspective. Found Sci. 2019. [CrossRef]

21. Camelia, D. Grey systems theory in economics a historical applications review. Grey Syst. Theory Appl. 2015, 5, 263-276. [CrossRef]

22. Liu, S.; Forrest, J. The current developing status on Grey system theory. J. Grey Syst. 2007, 19, 111-123.

23. Wang, X.; Qi, L.; Chen, C.; Tang, J.; Jiang, M. Grey System Theory based prediction for topic trend on Internet. Eng. Appl. Artif. Intell. 2014, 29, 191-200. [CrossRef]

24. Xia, X. Scientific View in Grey System Theory. ASS 2012, 8, 103. [CrossRef]

25. Wang, J.; Yan, R.; Hollister, K.; Zhu, D. A historic review of management science research in China. Omega 2008, 36, 919-932. [CrossRef] 
26. Hsu, L.C.; Wang, C.H. Forecasting integrated circuit output using multivariate grey model and grey relational analysis. Expert Syst. Appl. 2009, 36, 1403-1409. [CrossRef]

27. Liu, S.; Sheng, K.; Forrest, J. On uncertain systems and uncertain models. Kybernetes 2012, 41, 548-558. [CrossRef]

28. Duran, E.; Duran, U.B.; Akay, D.; Boran, F.E. Grey relational analysis between Turkey's macroeconomic indicators and domestic savings. Grey Syst. Theory Appl 2017, 7, 45-59. [CrossRef]

29. Maity, S.R.; Chatterjee, P.; Chakraborty, S. Cutting tool material selection using grey complex proportional assessment method. Mater. Des. (1980-2015) 2012, 36, 372-378. [CrossRef]

30. Liu, S.; Forrest, J.; Yang, Y. A brief introduction to grey systems theory. Grey Syst. Theory Appl. 2012, 2, 89-104. [CrossRef]

31. Moher, D.; Liberati, A.; Tetzlaff, J.; Altman, D.G. Preferred Reporting Items for Systematic Reviews and Meta-Analyses: The PRISMA Statement. J. Clin. Epidemiol. 2009, 62, 1006-1012. [CrossRef]

32. Rahman, M.D.H.; Tumpa, T.J.; Ali, S.M.; Paul, S.K. A grey approach to predicting healthcare performance. Measurement 2019, 134, 307-325. [CrossRef]

33. Wey, W.M. Constructing urban dynamic transportation planning strategies for improving quality of life and urban sustainability under emerging growth management principles. Sustain. Cities Soc. 2019, 44, 275-290. [CrossRef]

34. Zhang, Y.; Wang, Y.; Liu, Q. Grey game research about customer preference, international competition and the choice of industrial type. Grey Syst. Theory Appl. 2018, 8, 122-132. [CrossRef]

35. Shan, S.; Jia, Y.; Zheng, X.; Xu, X. Assessing relationship and contribution of China's technological entrepreneurship to socio-economic development. Technol. Forecast. Soc. Chang. 2018, 135, 83-90. [CrossRef]

36. Yu, Y.; Deng, Y.; Chen, F. Impact of population aging and industrial structure on CO 2 emissions and emissions trend prediction in China. Atmos. Pollut. Res. 2018, 9, 446-454. [CrossRef]

37. Wang, B.; Mi, Z.; Nistor, I.; Yuan, X.C. How does hydrogen-based renewable energy change with economic development? Empirical evidence from 32 countries. Int. J. Hydrogen Energy 2018, 43, 11629-11638. [CrossRef]

38. Soni, V.; Singh, S.P.; Banwet, D.K. Enlightening grey portions of energy security towards sustainability. Int. J. Energy Sect. Manag. 2017, 11, 118-142. [CrossRef]

39. Eren, M.; Kaynak, S. An evaluation of EU member states according to human development and global competitiveness dimensions using the multi-period grey relational analysis (MP-GRA) technique. Grey Syst. Theory Appl. 2017, 7, 60-70. [CrossRef]

40. Li, X.; Zheng, W.; Yin, L.; Yin, Z.; Song, L.; Tian, X. Influence of Social-economic Activities on Air Pollutants in Beijing, China. Open Geosci. 2017, 9, 314-321. [CrossRef]

41. Wang, C.N.; Nguyen, H.K. Enhancing Urban Development Quality Based on the Results of Appraising Efficient Performance of Investors-A Case Study in Vietnam. Sustainability 2017, 9, 1397. [CrossRef]

42. Soni, V.; Dey, P.K.; Anand, R.; Malhotra, C.; Banwet, D.K. Digitizing grey portions of e-governance. Transform. Gov. 2017, 11, 419-455. [CrossRef]

43. Delcea, C. Grey social media engagement analysis. Grey Syst. Theory Appl. 2016, 6, 233-245. [CrossRef]

44. Li, L.; Wang, R.; Li, X. Grey fuzzy comprehensive evaluation of regional financial innovation ability based on two types weights. Grey Syst. Theory Appl. 2016, 6, 187-202. [CrossRef]

45. Mao, S.; Gao, M.; Zhu, M. The impact of R\&D on GDP study based on grey delay Lotka-Volterra model. Grey Syst. Theory Appl. 2015, 5, 74-88.

46. Guo, K.; Zhang, Q. Detecting communities in social networks by local affinity propagation with grey relational analysis. Grey Syst. Theory Appl. 2015, 5, 31-40. [CrossRef]

47. Zhang, $Q$. The effects of financial deepening on income inequality based on grey incidence analysis: Empirical evidence from China. Grey Syst. Theory Appl. 2014, 4, 495-504. [CrossRef]

48. Li, J.S.; He, P.P.; He, R.B. Theoretical and empirical analysis of the supplier induced demand in health care market in China. Grey Syst. Theory Appl. 2014, 4, 207-220. [CrossRef]

49. Wang, Z.X.; Pei, L. A systems thinking-based grey model for sustainability evaluation of urban tourism. Kybernetes 2014, 43, 462-479. [CrossRef]

50. Wang, Y.; Tang, J.; Cao, W. Grey prediction model-based food security early warning prediction. Grey Syst. Theory Appl. 2012, 2, 13-23. [CrossRef]

51. Huang, J.C. Application of grey system theory in telecare. Comput. Biol. Med. 2011, 41, 302-306. [CrossRef] 
52. Scarlat, E.; Delcea, C. Complete analysis of bankruptcy syndrome using grey systems theory. Grey Syst. Theory Appl. 2011, 1, 19-32. [CrossRef]

53. Liu, Y.; Yao, C.; Wang, G.; Bao, S. An integrated sustainable development approach to modeling the eco-environmental effects from urbanization. Ecol. Indic. 2011, 11, 1599-1608. [CrossRef]

54. Kreng, V.B.; Yang, C.T. The equality of resource allocation in health care under the National Health Insurance System in Taiwan. Health Policy 2011, 100, 203-210. [CrossRef]

55. Yin, K.; Li, X.; Zhang, G.; Xiao, L. Analysis of socio-economic driving forces on built-up area expansion in Xiamen. Int. J. Sustain. Dev. World Ecol. 2010, 17, 279-284. [CrossRef]

56. Huang, J.; Wang, R.; Shi, Y. Urban climate change: A comprehensive ecological analysis of the thermo-effects of major Chinese cities. Ecol. Complex. 2010, 7, 188-197. [CrossRef]

(C) 2019 by the authors. Licensee MDPI, Basel, Switzerland. This article is an open access article distributed under the terms and conditions of the Creative Commons Attribution (CC BY) license (http://creativecommons.org/licenses/by/4.0/). 